\title{
Reproduction and immature development of Hyssopus pallidus (Hymenoptera: Eulophidae), an ectoparasitoid of the codling moth
}

\author{
KATHRIN TSCHUDI-REIN and SILVIA DORN \\ Institute of Plant Sciences, Applied Entomology, Swiss Federal Institute of Technology (ETH), Clausiusstrasse 25/NW, CH-8092 \\ Zurich, Switzerland; e-mail: kathrin.tschudi-rein@ipw.agrl.ethz.ch
}

Key words. Hyssopus pallidus, Eulophidae, larval ectoparasitoid, idiobiont, synovigenic, egg load, development, larval morphology, codling moth, Cydia pomonella

\begin{abstract}
Hyssopus pallidus (Askew) (Hymenoptera: Eulophidae) is a gregarious ectoparasitoid of late larvae of the codling moth, Cydia pomonella (L.) (Lepidoptera: Tortricidae). In the present work reproduction and the development and morphology of the immature stages were studied. Five larval instars were differentiated by the shape and size of the mandibles. The larvae are hymenopteriform with a weakly sclerotized head and 13 segments. The first instar has four pairs of spiracles, while the other four instars have nine pairs. Under laboratory conditions of $22-24^{\circ} \mathrm{C}$ and $60-80 \% \mathrm{RH}$ the egg stage lasted 1.5 days, the larval instars 6.3 days, and the pupal stage 7.9 days in females and 7.2 days in males. The duration of each of the five larval instars (L1-L5) is approximately $1,0.5,0.75,0.75$ and 3.5 days, respectively. Male and female development time does not differ significantly in the egg and larval stages, but differences are highly significant in the pupal stage. Male and female pupae can be differentiated by their sexual rudiments. Copulation takes place immediately upon emergence of the females between siblings, adult males appearing before the females. Females in culture with access to an energy source can survive for more than 60 days. They are synovigenic: they emerge with no mature eggs in their ovaries and take the first two days after emergence to mature the full set of around 24-30 eggs. They continue paralyzing hosts, ovipositing and maturing eggs for as long as they live. After an oviposition a female needs two to three days to mature a new full set of eggs. Age and feeding influence egg load. Oösorption is significant in starved females, but also occurs in older fed females with no host contact.
\end{abstract}

\section{INTRODUCTION}

The reproductive success of many hymenopterous parasitoids is influenced by supplemental feeding (reviewed by Thompson, 1999). Adult females obtain essential nutrients by feeding on sugar sources and in some species by feeding on the hemolymph of their hosts (Jervis \& Kidd, 1986; Jervis et al., 1996). Host-feeding is frequently found in idiobionts, as these are predominantly synovigenic, produce large protein-rich eggs and thus often need extra proteins to mature more oocytes (Jervis \& Kidd, 1986; Quicke,1997). Most studies of the effects of adult feeding on lifetime reproductive success have shown that, for host-feeding species, sugar meals increase longevity, while host-feeding provides materials used for egg maturation (reviewed by Heimpel et al., 1997). Sugar sources, though, can also have a direct influence on the number of mature eggs a female carries, as for example in species with oösorption (Edwards, 1954) and in species that have to feed first after eclosion, in order to mature their eggs (Mao \& Kunimi, 1994). Knowledge of these factors is important, as they may influence the success of an antagonist released as a biological measure in the field.

The immature stages of hymenopterous endo- and ectoparasitoids are often difficult to identify. In the ectoparasitoid species of the superfamily Chalcidoidea morphological characters for instar differentiation are lacking. The larvae are usually only weakly sclerotized. Even the heads have few sclerotized structures other than the mandibles. Thus morphometric studies, applying Dyar's law, cannot be carried out, aside for a few exceptions (Saunders, 1960). Data on the number of larval instars of hymenopterous parasitoids is scarce and not all published records are reliable (reviewed by Quicke, 1997). The plesiomorphic number of larval instars appears to be five (Hagen, 1964).

Hyssopus pallidus (Askew) (Hymenoptera: Eulophidae) is a gregarious ectoparasitoid of late larval instars of the codling moth, a widely distributed major fruit pest (Brown, 1996). It can lower the infestation rate of its host to a level that allows the successful employment of the mating disruption technique. Pheromone-based mating disruption is only successful with low codling moth population levels (Charmillot, 1990; Vickers \& Rothschild, 1991). Judd et al. (1997) report good results in British Columbia with a combination of mating disruption, tree banding and post-harvest fruit removal (sanitation). Yet the two latter methods are labor intensive and therefore costly. One or even both of the methods could be substituted by augmentative release of parasitoids such as $H$. pallidus ( Mattiacci et al., 1999).

The species was first described by Askew (1964) from females reared from larvae of Cydia pomonella and Cydia (Grapholita) molesta. Zaviezo \& Mills (1999) reported on the effect of temperature on development, the effect of different food sources on longevity and the potential fecundity of the female. The main objective of this study was to analyse the reproductive biology of the adult parasitoid and the developmental biology and morphology of the immature stages. 


\section{MATERIALS AND METHODS}

\section{Insect cultures}

The Cydia pomonella were from a colony established in the laboratory $\left(23 \pm 2^{\circ} \mathrm{C}, 60 \pm 10 \% \mathrm{RH}, 18 \mathrm{~L}: 6 \mathrm{D}\right)$. The larvae were reared on a semi-synthetic medium according to Huber et al. (1972). To obtain diapausing fifth larval instars, larvae were held at $23 \pm 2{ }^{\circ} \mathrm{C}, 60-70 \% \mathrm{RH}$, with a $8 \mathrm{~L}: 16 \mathrm{D}$ photoperiod from the first instar. They were then stored at $4{ }^{\circ} \mathrm{C}$.

The Hyssopus pallidus used in this study were from a starter colony provided in 1996 by T. Unruh (USDA-ARS Research Laboratory, Wapato, USA). The original parasitoids had been collected in the field in France. Diapausing fifth instar codling moth larvae were offered as hosts to mated female parasitoids, or to virgin females if only male progeny were required. Undiluted honey and water were given ad libitum. The culture was kept in a climatic chamber at $22-24^{\circ} \mathrm{C}, 60-80 \% \mathrm{RH}$, with a $16 \mathrm{~L}: 8 \mathrm{D}$ photoperiod. All experiments were carried out under these same conditions with parasitoids that had not had prior access to hosts.

\section{Reproductive biology}

Adult female longevity and egg load were studied in both honey-fed and starved parasitoids. Females were separated upon emergence and mating, and either given drops of undiluted honey and water (fed group) or only water (starved group). They were monitored daily for mortality. At least ten females from each group were dissected on days 0 (day of emergence), 1 and 2, and 20 females from each group on days 4,6 and 7. As unfed females died within 6-7 days, only seven instead of 20 females in the "starved" group could be dissected on day 7. In addition, six and nine females from the "fed" group were dissected on day 27 and 60 , respectively. The number of mature eggs in the ovarioles was recorded. Signs of oösorption were noted separately. The few females with more than the usual three ovarioles per ovary were not included in this experiment.

The time required after ovipostion to mature a new set of eggs was also recorded. Two-day old fed and mated females were each offered a diapausing fifth instar host larva in a petri dish of $3 \mathrm{~cm}$ diameter containing a drop of honey. After oviposition the females were held individually without host. The number of eggs oviposited by each female was noted. Only females that had produced at least ten eggs were included in this experiment. At least ten females were dissected 1,2 and 3 days post oviposition respectively, with day 1 post oviposition defined as 24 to $36 \mathrm{~h}$ after oviposition. The number of mature eggs in the ovarioles was counted.

\section{Immature development}

A diapausing fifth instar host larva in a $3 \mathrm{~cm}$ petri dish with a drop of honey was offered to a 2-3 day old, mated female $H$. pallidus. Every $12 \mathrm{~h}$, the petri dish was controlled. Paralysis of the host and oviposition were recorded and the female then removed. All but one freshly hatched parasitoid larvae were eliminated. Comparison with normally developing parasitoid larvae showed that this did not influence total development time, nor did it influence the size of the ensuing pupae. We hoped to find a means of differentiating the instars without having to sacrifice them for studying under a microscope. Preliminary attempts to observe moultings on living larvae had failed. The larvae were too weakly sclerotized and they could not be marked with any dyes, as even powder dyes were quickly eliminated from the smooth body surface. The following parameters were recorded at each $12 \mathrm{~h}$ check: (1) the duration of the different stages, i.e. egg, larval and pupal stage, (2) maximum body length and (3) maximum body width of the developing larva and of the ensuing pupa. Measurements were made with an eyepiece graticule under a binocular microscope at 50x magnification. Thirtyone individual larvae were observed thru to the adult moult. The sex was noted at the earliest possible time, namely in the pupal stage. Of the 31 parasitoids observed, 29 were females and only 2 males. Thus an additional 36 male larvae from virgin females were studied as described above. The species is arrhenotokous and virgin females only produce male progeny.

In addition, the size of male and female pupae were studied in the progeny of 2- to 3-day old mated female wasps that were reared on individual fifth instar host larvae.

Morphological characters were studied on fresh total preparations of parasitoid larvae under a light microscope (Olympus BX50 with attached Olympus photoequipment). Older larvae were placed in a drop of $10 \% \mathrm{KOH}$. Measurements (maximum body length and width) of the larvae were always taken before the preparations were made. Sexing was not possible so early in development.

Preliminary trials using scanning electron microscopy proved this method to be less suitable for studying the larval mouthparts. The mandibles are retracted when not in use and are not visible from the outside.

\section{RESULTS}

\section{Reproductive biology}

Two-way ANOVA shows that egg load is significantly influenced by age $(\mathrm{F}=22.42, \mathrm{df}=4,152, \mathrm{P}<0.0001)$ and

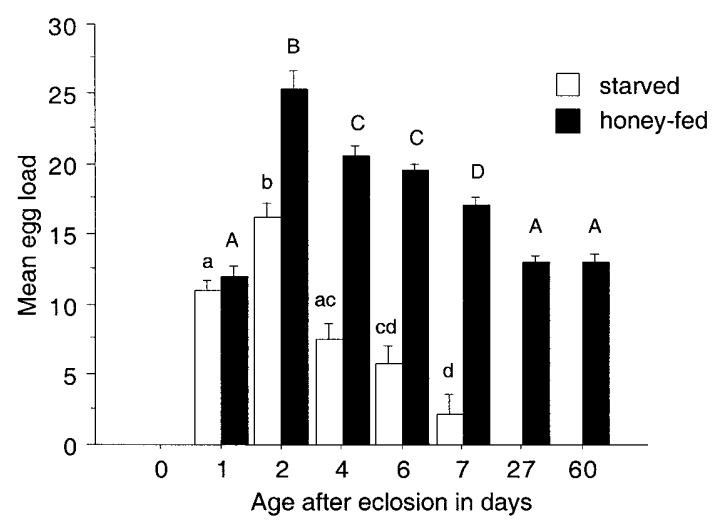

Fig. 1. Effect of feeding and age on egg load (mean \pm SE) in Hyssopus pallidus. Starved females died within 7 days, while honey-fed females lived for up to 60 days. Females of both groups had no host contact. Different letters above bars show significant differences in egg load (Fischer's PLSD).

by feeding ( $\mathrm{F}=202.51$, $\mathrm{df}=1,152, \mathrm{P}<0.0001)$. As Fig.1 shows, egg load decreased in both groups with age, but significantly faster in starved females.

Hyssopus pallidus females are synovigenic. Newly emerged females had no mature eggs at all in their ovarioles $(\mathrm{N}=11)$, while two-day old honey-fed females had a mean egg load of $25.4 \pm 1.3($ mean $\pm \mathrm{SE}, \mathrm{N}=11$ ). This corresponds well with the mean number of $21 \pm 1.6$ eggs deposited by three-day old mated females on a first host $(\mathrm{N}=14$; honey and water given ad libitum). Females continue to produce and lay eggs on hosts for as long as they live.

Analysis of egg maturation after an oviposition showed that females need around three days to fill their ovarioles 
with mature eggs. Three days after an oviposition the egg load was $26.7 \pm 0.9$ (mean $\pm \mathrm{SE}, \mathrm{N}=11$ ) which is significantly more than on day one post oviposition with $13.5 \pm 1.1(\mathrm{~N}=10)$ and day two with $21.6 \pm 0.6(\mathrm{~N}=11)$ (Kruskal-Wallis test: $\mathrm{H}=25.31, \mathrm{P}<0.0001$; Mean Rank: day $3>$ day $2>$ day 1 ).

\section{Immature development}

Five larval instars were identified by the size and shape of their toothlike mandibles (Figs. 2, 3c). Exuviae from first and successive instars that were sometimes found hanging on to a larva helped confirm this number. The larvae of $H$. pallidus (Figs. 3a, b) are sac-like grubs, hymenopteriform according to the classification of Clausen (1962), with a weakly sclerotized head and 13 segments, i.e. three thoracic and ten abdominal. They have an open tracheal system. Segments two to ten are equipped with a pair of spiracles (Fig. 3d) in all but the first larval instar, which only has a pair of spiracles in the 2nd, 4th, 5th and 6th segment. This is like other Chalcidoidea belonging to Group I of the classification of Parker (1924). In the second and third larval instars the additional spiracles are still clearly smaller in size than the initial four pairs of the first instar.

H. pallidus is an idiobiont and prior to oviposition the host larva is irreversibly paralysed by the female parasitoid. Under the given conditions from six to 30 elongated eggs, $0.34 \pm 0.002 \mathrm{~mm}$ long in both sexes (mean $\pm \mathrm{SE}, \mathrm{N}=12$ ) and with thin and transparent chorion, are deposited onto the host or close by. Table 1 lists for male and female $H$. pallidus the development time of the different immature stages and the size of the egg and pupa. Male and female egg and larval development times do not differ significantly, but male
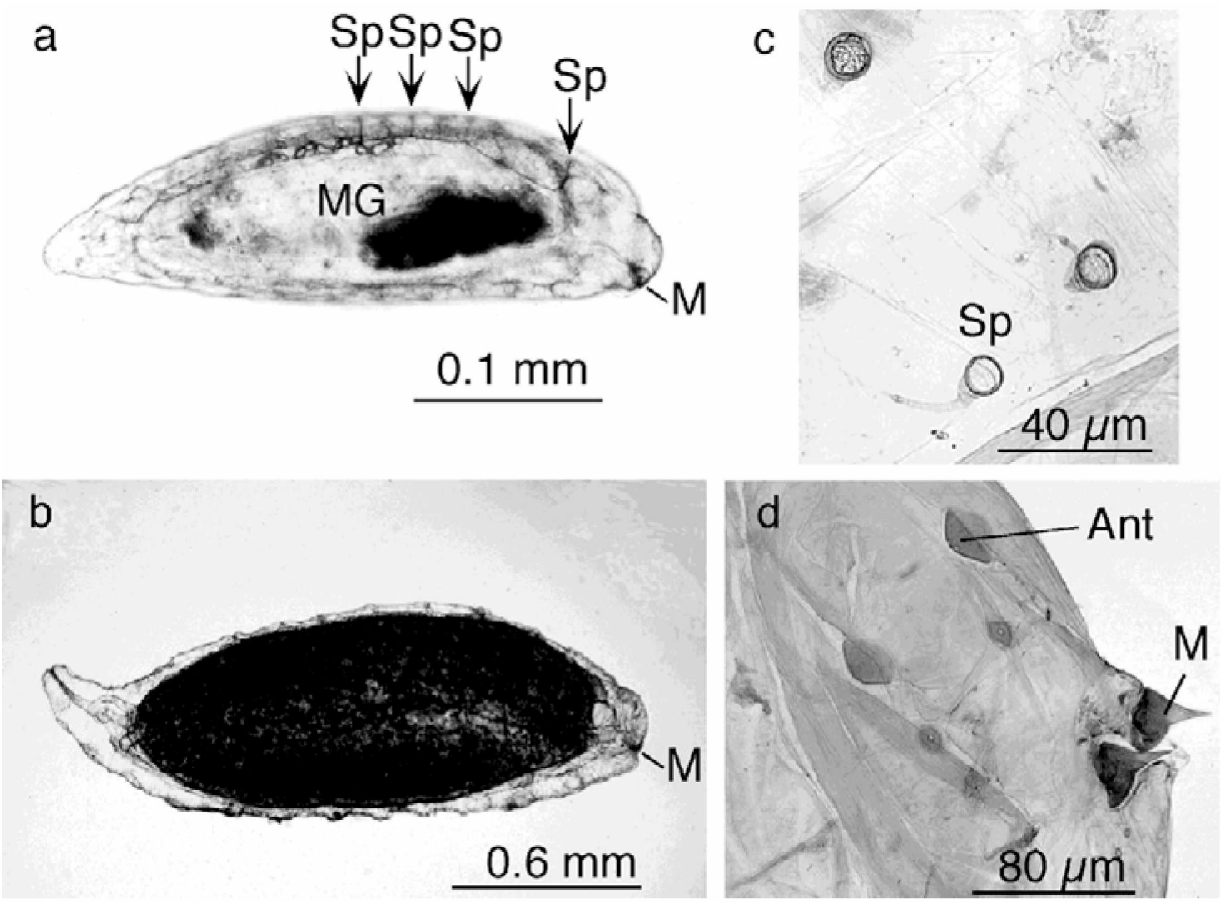

Fig. 3. Hyssopus pallidus first (a) and fifth instar larva (b-d). a - general view of first instar larva showing spiracles in 2 nd and 4th-6th segments; $b$ - general view of fifth and final larval instar (L5); $c$ - spiracle in 3rd segment (above are spiracles of 3rd and 4 th segment of other body side); $\mathrm{d}$ - head laterally compressed with mandibles folded out. Ant - Antenna, M - Mandible, MG Midgut, Sp - Spiracle. 
TABLE. 1. Development time and body size of immature stages of male and female Hyssopus pallidus

\begin{tabular}{|c|c|c|c|c|c|c|c|}
\hline \multirow{2}{*}{\multicolumn{2}{|c|}{ Stage Sex }} & \multicolumn{3}{|c|}{ Development time } & \multicolumn{3}{|c|}{ Body length } \\
\hline & & $\mathrm{N}$ & Mean \pm SE (in days) & $\mathrm{P}^{*}$ & $\mathrm{~N}$ & Mean \pm SE (in $\mathrm{mm}$ ) & $\mathrm{P}$ \\
\hline \multirow[t]{2}{*}{ Egg } & $\mathrm{M}$ & 38 & $1.49 \pm 0.02$ & $\mathrm{a}$ & 12 & $0.34 \pm 0.002$ & $\mathrm{e}$ \\
\hline & $\mathrm{F}$ & 29 & $1.48 \pm 0.01$ & $\mathrm{a}$ & 12 & $0.34 \pm 0.002$ & $\mathrm{e}$ \\
\hline \multirow[t]{2}{*}{ Larva } & M & 37 & $6.26 \pm 0.08$ & b & & & \\
\hline & $\mathrm{F}$ & 29 & $6.35 \pm 0.10$ & b & & & \\
\hline \multirow[t]{2}{*}{ Pupa } & M & 37 & $7.16 \pm 0.04$ & $\mathrm{c}$ & 35 & $1.79 \pm 0.016$ & $\mathrm{f}$ \\
\hline & $\mathrm{F}$ & 20 & $7.85 \pm 0.08$ & d & 160 & $2.15 \pm 0.006$ & g \\
\hline
\end{tabular}

* Means followed by the same letters are not significantly different, those with different letters are at $\mathrm{P}<0.0001$ (Mann-Whitney U test)

2.25 days after hatching, at a body length of $0.92-1.0 \mathrm{~mm}$ and a max. width of around $0.38-0.4 \mathrm{~mm}$. The moult to the fifth and final instar is $18 \mathrm{~h}$ later, 3 days after hatching, at a body length of $1.4-1.5 \mathrm{~mm}$ and a max. width of $0.52-0.58 \mathrm{~mm}$, males being slightly smaller than females. Around 3.5 days later, i.e. $6.3 \pm 0.1$ days after hatching, the larvae enter the pupal stage. Two days prior to this they had dropped off the usually exhausted remains of their host. The hitherto blind-ending gut was emptied of the meconium (first a yellow gelatinous substance is expelled and then the dark gut contents) while the larvae slowly became condensed and thus shrank in size ("prepupal phase").

Freshly pupated individuals are white and slowly darken as the cuticula is sclerotized from a light gray to black. They are of the exarate, free type. Male and female pupae (Fig. 5) can easily be differentiated by their sexual rudiments located ventrally on the ninth abdominal segment. Those of the females consist of two raised globular structures, while those of the males are flatter and more compact in comparison. Male and female pupae also differ significantly in length with $1.79 \pm 0.016 \mathrm{~mm}$ and $2.15 \pm 0.006 \mathrm{~mm}$ resp (Table 1 ).

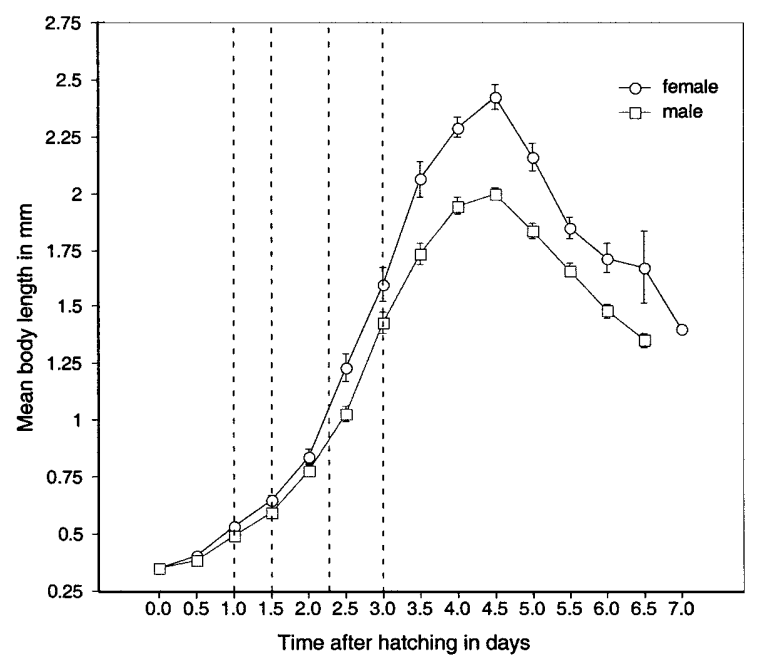

Fig. 4. Larval growth pattern. Maximum body length (mean $\pm \mathrm{SE}, \mathrm{N}$ males $=37, \mathrm{~N}$ females $=29$ ) of single male and female $H$. pallidus larvae measured every $12 \mathrm{~h}$ from hatching to pupation. Dashed vertical lines show larval moults.

\section{DISCUSSION}

The five larval instars of Hyssopus pallidus are difficult to differentiate. Such morphological characters as sclerotized head capsules are lacking. The larvae had to be sacrificed and studied under a microscope. For the given culture temperature, though, time after hatching and max. body length can now help to identify the larval instar. In other Eulophidae from three to five instars were found (Aeschlimann, 1969; Clausen, 1962; Delanoue \& Arambourg, 1967; Parker, 1924), with endoparasitic species tending to have three and ectoparasitic five larval instars.

As in $H$. pallidus, male and female pupae of other eulophid species can also be differentiated by the sexual rudiments on the tip of their abdomen. The illustrations of the pupae of the three species treated by Aeschlimann (1969), namely Elachertus argissa, Sympiesis punctifrons and Dicladocerus westwoodii, and the illustration of the pupa of Pnigalio mediterraneus by Delanoue \& Arambourg (1967) all show these characters too. Zaviezo \& Mills (1999) differentiated between male and female pupae of $H$. pallidus, but failed to mention how they did this.

The development times we obtained for the different immature stages at $22-24^{\circ} \mathrm{C}, 60-80 \% \mathrm{RH}$ fit well into the curves of Zaviezo \& Mills (1999) showing the effect of temperature on the duration of egg, larval and pupal development. We found that $H$. pallidus required high $\mathrm{RH}$ levels, especially for those immature stages that were not feeding.

The absence of hosts to oviposit on may be at least partly responsible for the reduced egg load in older honey-fed $H$. pallidus females. Egg quality possibly decreases with egg age and thus the eggs are resorbed. Zaviezo \& Mills (1999) observed host feeding in this species in connection with brood guarding which lasted for up to $24 \mathrm{~h}$ after oviposition. The results of their experiments show that host feeding does not contribute to
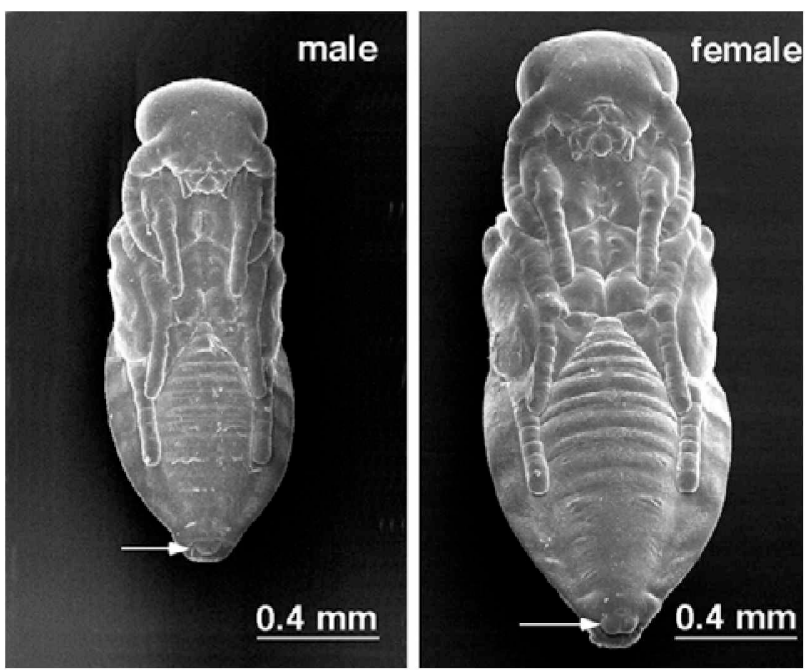

Fig. 5. General view of male and female pupae of H. pallidus. Arrows point to sexual rudiments. 
female parasitoid longevity, but they did not analyse its effect on egg load. Synovigenic parasitoids not only require materials for survival, but also for egg production. Although our own observations of host-feeding were rare and sporadic, host hemolymph could be an important energy source for egg maturation in $H$. pallidus, as was found by Heimpel et al. (1997) in Aphytis melinus DeBach.

Since the behaviour of a female parasitoid will not only be influenced by the host itself and by the host-foodplant (Mattiacci et al., 2000) but obviously also by the condition of her ovaries, it is important to know what changes occur in the ovaries with increased age and with different diets. This information is also important for the planning and evaluation of behavioral studies. In $H$. pallidus under the given culture conditions three factors must be taken into consideration: (1) females need two days of feeding after eclosion to produce a full set of mature eggs, (2) lack of a host can with time negatively influence the quality and number of mature eggs available as eggs are resorbed and (3) females need 2 to 3 days after an oviposition to produce a new set of mature eggs.

ACKNOWLEDGEMENTS. We thank P. Egli, E. Hütter and T. Kuske for help with rearing and data collection. Special thanks go to H. Gu for help with the statistics, to L. Mattiacci for valuable discussions and to her and $\mathrm{R}$. Camenzind for comments to an earlier draft of the manuscript.

\section{REFERENCES}

Aeschlmann J.P. 1969: Contribution a l'étude de trois éspèces d'Eulophides (Hym. Chalcidoidea) parasites de la Tordeuse grise du Mélèze, Zeiraphera dimiana Guenee (Lep. Tortricidae) en Haute-Engadine. Entomophaga 14: 261-320.

ASKEW R.R. 1964: On the biology and taxonomy of some European species of the genus Elachertus spinola (Hymenoptera: Eulophidae). Bull. Entomol. Res. 55: 53-58.

BRown J.J. 1996: The compatibility of tebufenozide with a laboratory lepidopteran host/hymenopteran parasitoid population. Biol. Control 6: 96-104.

Charmillot P.-J. 1990: Mating disruption technique to control codling moth in western Switzerland. In Ridgway R.L., Silverstein R.M. \& Inscoe M.N. (eds): Behavior-modifying Chemicals for Insect Management: Applications of Pheromones and other Attractants. Dekker, New York, pp. 165-182.

Clausen C.P. 1962: Entomophagous Insects. McGraw-Hill Book Co., Inc., New York, London, 688 pp.

Delanoue P. \& Arambourg Y. 1967: Contribution à l'étude en laboratoire de Pnigalio mediterraneus (Hym. Chalcidoidea
Eulophidae). Ann. Soc. Entomol. Fr. 3: 909-927.

EDWARDS R.L. 1954: The effect of diet on egg maturation and resorption in Mormoniella vitripennis (Hymenoptera, Pteromalidae). Q. J. Microsc. Sci. 95: 459-468.

HAGEN K.S. 1964: Developmental stages of parasites. In DeBach P. (eds): Biological Control of Insect Pests and Weeds. Chapman and Hall, London, pp. 168-246.

Hempel G.E., Rosenherm J.A. \& Kattari D. 1997: Adult feeding and lifetime reproductive success in the parasitoid Aphytis melinus. Entomol. Exp. Appl. 83: 305-315.

Huber J., Benz G. \& Schmid K. 1972: Zuchtmethode und semisynthetische Nährmedien für Apfelwickler. Experientia 28: $1260-1261$

JERVIS M.A. \& KDD N.A.C. 1986: Host-feeding strategies in hymenopteran parasitoids. Biol. Rev. 61: 395-434.

Jervis M.A., Kidd N.A.C. \& HeImpel G.E. 1996: Parasitoid adult feeding behaviour and biocontrol - a review. Biocontrol News Inf. 17: 11-22.

Judd G.J.R., Gardiner M.G.T. \& Thomson D.R. 1997: Control of codling moth in organically managed apple orchards by combining pheromone mediated mating disruption, post harvest fruit removal and tree banding. Entomol. Exp. Appl. 83: 137-146.

Mao H. \& KunimI Y. 1994: Longevity and fecundity of Brachymeria lasus (Walker) (Hymenoptera: Chalcidoidea), a pupal parasitoid of the oriental tea tortrix, Homona magnanima Diakonoff (Lepidoptera: Tortricidae) under laboratory conditions. Appl. Entomol. Zool. 29: 237-243.

Mattiacci L., Hưtter E. \& Dorn S. 1999: Host location of Hyssopus pallidus, a larval parasitoid of the codling moth, Cydia pomonella. Biol. Control 15: 241-251.

Mattiacci L., Hütter E., Schoch D., Scascighin N. \& Dorn S. 2000: Plant-odour mediated parasitoid reproduction in an endophytic system. Chemoecology 10: 185-192.

PARKER H.L. 1924: Recherches sur les formes post-embryonnaires des Chalcidiens. Ann. Soc. Entomol. Fr. 93 : 261-379.

Quicke D.L.J. 1997: Parasitic Wasps. Chapman \& Hall, London, $470 \mathrm{pp}$.

SAUNDERS D.S. 1960: On the stages in the development of Syntomosphyrum albiclavus KERRICH (Hym., Eulophidae), a parasite of tsetse flies. Bull. Entomol. Res. 51: 25-31.

THOMPSON S.N. 1999: Nutrition and culture of entomophagous insects. Annu. Rev. Entomol. 44: 561-592.

VICKERS R.A. \& RothschILD G.H.L. 1991: Use of sex pheromones for control of codling moth. In van der Geest L.P.S. \& Evenhuis H.H. (eds): World Crop Pests: Tortricid Pests, Vol. 5. Elsevier, Amsterdam, pp. 339-354.

ZAVIEZo T. \& Mills N. 1999: Aspects of the biology of Hyssopus pallidus (Hymenoptera: Eulophidae), a parasitoid of the codling moth (Lepidoptera: Olethreutidae). Envir. Entomol. 28: 748-754.

Received February 28, 2000; revised June 22, 2000; accepted July 21, 2000 